\title{
The Number of Syncytial Knots and VEGF Expression in Placental Villi in Parturient Woman with COVID-19 Depends on the Disease Severity
}

\author{
A. I. Shchegolev, G. V. Kulikova, V. M. Lyapin, R. G. Shmakov, \\ and G. T. Sukhikh
}

Translated from Byulleten' Eksperimental'noi Biologii i Meditsiny, Vol. 171, No. 3, pp. 386-390, March, 2021 Original article submitted February 9, 2021

\begin{abstract}
A comparative morphological study was carried out to analyze the number of syncytial knots and VEGF expression in placental villi in parturient women with COVID-19 categorized by the disease severity. The number of syncytial knots was assessed on specimens stained with hematoxylin and eosin. VEGF expression was determined by immunohistochemical analysis in syncytiotrophoblast and villous endothelial cells. Morphological study of the placenta tissue of parturient women with COVID-19 showed increased numbers of syncytial knots in the villi, indicating the development of preplacental hypoxia. High VEGF expression in syncytiotrophoblast and vascular endotheliocytes reflects a stereotyped response to hypoxia and can underlie the development of a preeclampsia-like syndrome. The number of syncytial knots and VEGF expression in placental villi in parturient women with COVID-19 depended on the disease severity.
\end{abstract}

Key Words: novel coronavirus infection (COVID-19); SARS-CoV-2; placenta; syncytial knots; VEGF

Novel coronavirus infection (COVID-19) first occurred in December 2019, and three months later, the outbreak was declared a pandemic of SARS-CoV-2 by the World Health Organization [5]. The most important manifestations of COVID-19 are lung lesions, development of pneumonia and/or acute respiratory distress syndrome, and coagulation disorders with the development of hypercoagulability [13]. Pregnant women are at particular risk due to the development of not only lesions in organs and tissues typical of SARS-CoV-2 infection, but also placental and fetal complications.

According to some publications [3], most common placental injury in pregnant women with COVID-19 is impaired blood flow in maternal uteroplacental compartment and development of inflammatory

V. I. Kulakov National Medical Research Center for Obstetrics, Gynecology and Perinatology, Ministry of Health of the Russian Federation, Moscow, Russia. Address for correspondence: patan777@gmail.com. A. I. Shchegolev changes consequently resulting in the formation of hypoxic zones both in placental and fetal structures.

It is believed that morphological indicators of preplacental hypoxia and placental ischemia are increased numbers of syncytial knots [14] and high vascular endothelial growth factor (VEGF) expression levels in placental villi [15].

The aim of the study was a comparative analysis of the number of syncytial knots and VEGF expression in placental villi in parturient women with COVID-19 depending on the disease severity.

\section{MATERIALS AND METHODS}

The study is based on the morphological analysis of 30 placentas after term births in women, who were divided into three groups. Group 1 included placentas from 6 patients (age 24-42 years, mean 29.8 \pm 6.1 years), who had moderate COVID-19 symptoms during childbirth, group 2 included placentas from 17 patients 
(age 26-48 years, mean $34.3 \pm 8.2$ years) with mild COVID-19 symptoms. The control group consisted of placentas from 7 patients (age 22-35 years, mean $28.7 \pm 4.9$ years) with normal pregnancy, who had no extragenital and genital pathology.

Macroscopic examination of placenta was performed according to generally accepted recommendations. After macroscopic examination, placental tissue specimens were excised from paracentral zone of the placental disc and fixed in $10 \%$ neutral formalin. Histological examination was performed on paraffin sections stained with hematoxylin and eosin. The number of syncytial knots and intervillous bridges (in \%) was assessed in the terminal and immature intermediate villi in the microscope field of view.

Immunohistochemical analysis was performed on 3-4 $\mu$ m-thick paraffin sections using automated ultraView Universal DAB Detection Kit system (Roshe), polyclonal rabbit anti-VEGF antibodies (Spring Bioscience), and polymer detection system (Spring Bioscience). Antigen unmasking was performed by boiling the samples in citrate buffer $(\mathrm{pH} 6.0)$; the sections were treated with $0.3 \%(\mathrm{v} / \mathrm{v}) \mathrm{H}_{2} \mathrm{O}_{2}$ for $15 \mathrm{~min}$ to block endogenous peroxidase activity. Hematoxylin was used as a basis of the dye.

Quantitative assessment of VEGF expression was performed in terminal (in syncytiotrophoblast and capillary endothelium) and stem (endothelium of arteries and veins) placental villi by optical density (OD) using Nikon Eclipse 80i microscope and Nikon NISElements Advanced Research 3.2 software for image analysis.

Statistical processing of quantitative data was performed using Statistica 8.0 software (StatSoft, Inc.). The mean values, standard deviation and the standard error of the mean were calculated; the differences were statistically significant at $p<0.05$.

\section{RESULTS}

In all observations, visual examination of histological preparations of the placental tissue stained with hematoxylin and eosin showed the presence of syncytial knots in the terminal and immature intermediate villi, and also in intervillous bridges. However, their number was different in the studied groups (Fig. 1. $a-c$ ).

Quantitative assessment showed that the number of syncytial knots was maximum in parturient women with moderate COVID-19 (group 1) and surpassed the corresponding parameter in group 2 and in the control group by 12.7 and $34.6 \%$, respectively $(p<0.01)$. In turn, the mean number of syncytial knots in the placental villi from parturient women with mild COVID-19 (group 2) exceeded the control values by $19.5 \%(p<0.01)$.
The number of intervillous syncytial bridges was maximum in parturient women with mild COVID-19 infection (group 2) and surpassed the control values by $94.7 \%(p<0.01)$ and the values in group 1 by $4.75 \%$ $(p>0.05)$.

Immunohistochemical analysis showed that the highest VEGF expression was observed in the cytoplasm of syncytiotrophoblast and trophoblast, as well as in vascular endotheliocytes (Fig. 1, $d-e$ ).

The quantitative assessment of immunohistochemical preparations showed high VEGF expression in structures of the placenta from parturient women with moderate of COVID-19 infection (Fig. 2). These values in syncytiotrophoblast were higher than in the control group and in group 2 by 41.3 and $19.3 \%$, respectively $(p<0.05)$, and in capillary endothelium in terminal villi by 19.4 and $12.7 \%$, respectively $(p<0.05)$. In stem villi, high VEGF expression in the endothelium of arteries and veins was also found in group 1: the values were higher than in the control group by 44.2 and $66 \%$, respectively $(p<0.05)$. In group 2 , expression of VEGF in endotheliocytes of arteries and veins in stem villi surpassed the corresponding levels in the control group by 25.6 and $26.6 \%$, respectively $(p<0.05)$.

Thus, histological analysis of placental preparations revealed higher number of syncytial knots and higher expression level of VEGF in placental villi in parturient women with COVID-19.

Syncytial (or syncytiotrophoblastic) knots are localized accumulations of syncytiotrophoblastic nuclei protruding into the intervillous space. Syncytial bridges are trophoblast elements linking adjacent villi. Syncytial knots reflect normal development of the placenta, however, in cases of hypoxia and ischemia of the placenta, their numbers increase. Greater number of syncytial knots in the placental villi were found in pregnant women living in high mountain areas [11] and in cases of fetal growth retardation [7].

In preeclampsia, the number of syncytial knots was also increased in observed [7]. At the same time, increased numbers of syncytial knots were significantly more often observed in late-onset preeclampsia compared to early-onset preeclampsia [1].

Due to this, syncytial knots are the most characteristic sign of changes in placental villi under conditions of reduced uteroplacental blood flow [2] and, accordingly, increased number of syncytial knots and bridges that was found in terminal villi, indicated placental hypoxia.

This conclusion is confirmed by the results of data analysis in publications on detected placental injuries in pregnant women with COVID-19 [3]. In most studies, the signs of impaired maternal blood flow (maternal vascular insufficiency) to the placenta were 

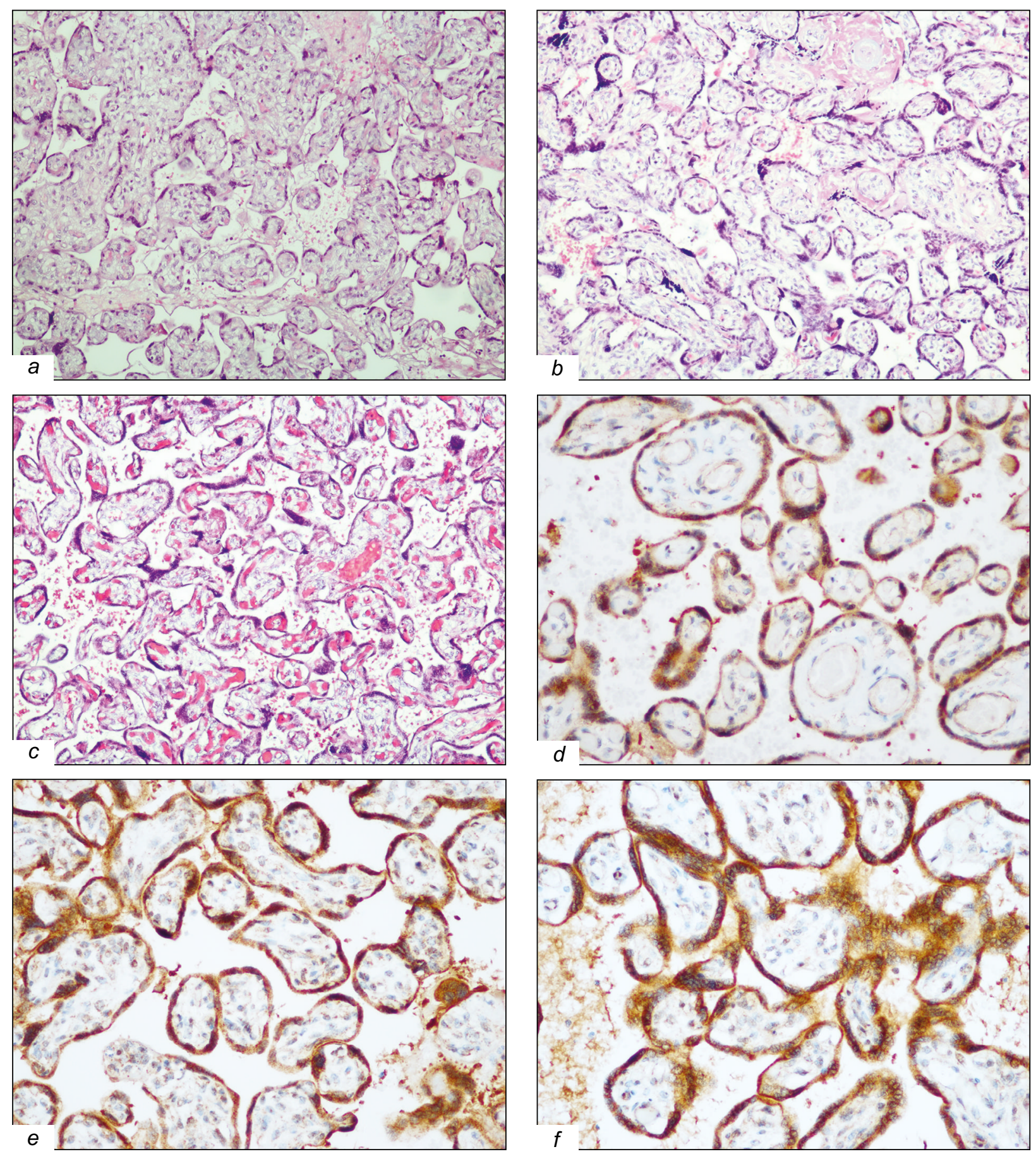

Fig. 1. Syncytial knots $(a-c)$ and VEGF expression $(d-f)$ in placental villi in parturient women in the control group (a, $d)$ and women with mild $(b, e)$ and moderate COVID-19 symptoms $(c, f)$. Hematoxylin and eosin staining, $\times 100$ (a-c); immunoperoxidase assay, $\times 100(d-f)$.

detected: decidual arteriopathy, accelerated villous maturation and distal villous hypoplasia, perivascular fibrin deposits and placental villous infarction.

It should be noted that similar changes in the placenta are observed in preeclampsia. Moreover, systematic review of published reports [6] on the course of pregnancy and outcomes in patients with coronavirus infections (SARS, MERS, or COVID-19) found symptoms of preeclampsia in $16.2 \%$ of observations. In a prospective study [12], the presence of clinical signs of preeclampsia were revealed that disappeared before the onset of labor after elimination of respiratory disorders in a number of pregnant women with severe symptoms of SARS-CoV-2. The term "preeclampsia- 


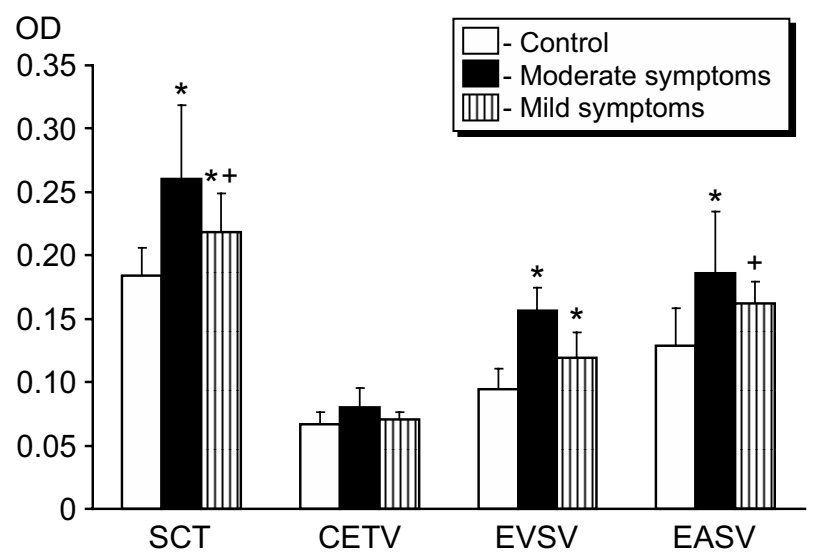

Fig. 2. Expression of VEGF in placental villi from parturient women with moderate and mild symptoms of COVID-19. SCT: syncytiotrophoblast, CETV: capillary endotheliocytes in terminal villi, EVSV: endotheliocytes of veins in stem villi, 4) EASV: endotheliocytes of arteries in stem villi.

like syndrome" was given to the changes that met the clinical criteria for preeclampsia.

It is most likely, that interaction between coronavirus SARS-CoV-2 with angiotensin converting enzyme 2 (ACE2) receptor located in placental cells underlies the development of preeclampsia-like syndrome in pregnant women with COVID-19 [8]. This interaction will consequently result in changes in its expression and disproportion in the ratio of angiotensin I and angiotensin II with a subsequent BP elevation as the main sign of preeclampsia.

Another mechanism of BP elevation can be a change in the expression levels of VEGF and its receptors in placental structures. It is known that the leading mechanism of a compensatory response to placental hypoxia is activation of VEGF pathway. Hence, the development of preeclampsia caused by decreased uteroplacental blood flow leads to changes in the expression of pro-angiogenic and anti-angiogenic mediators, and the main source of their production is syncytiotrophoblast. Increased levels of serum VEGF and soluble form of sFlt-1 promote the development of preeclampsia symptoms, in particular, BP elevation [4,9].

Our immunohistochemical study demonstrated increased level of VEGF expression mainly in syncytiotrophoblast of the terminal villi in parturient women with moderate COVID-19 to a greater extent than in women with mild disease severity. These changes, along with increased number of syncytial knots, also indicate the development of placental hypoxia in parturient women with COVID-19. In this regard, despite available published data on lesser susceptibility of the female body to coronavirus disease COVID-19, less severe symptoms and rare incidence of severe complications [10], it should be noted that preplacental hypoxia developed in all studied cases. Moreover, hypoxia promotes increased production of pro-angiogenic factors by placental cells, in particular, VEGF, which not only regulates proliferation and migration of endotheliocytes, but also contributes to BP elevation in pregnant women.

Thus, the morphological study of the placental tissue from parturient women COVID-19 revealed increased number of syncytial knots in the villi and intervillous bridges indicating the development of preplacental hypoxia. Immunohistochemical analysis showed enhanced expression of VEGF in the syncytiotrophoblast and capillary endotheliocytes in the villi reflected a stereotyped response to hypoxia and could underlie the development of preeclampsia-like syndrome in pregnant women. Increased numbers of syncytial knots and high VEGF expression levels in the placental villi in parturient women with COVID-19 depended on the disease severity.

\section{REFERENCES}

1. Shchegolev AI, Lyapin VM, Tumanova UN, Vodneva DN, Shmakov RG. Histological changes in the placenta and vascularization of its villi in early- and late-onset preeclampsia. Arkh. Patol. 2016;78(1):13-18. doi: 10.17116/patol201678113-18. Russian.

2. Shchegolev AI, Tumanova UN, Lyapin VN, Serov VN. The syncytiotrophoblast of the placental villi in health and in preeclampsia. Akush. Ginekol. 2020;(6):21-28. doi: 10.18565/ aig.2020.6.21-28. Russian.

3. Shchegolev AI, Tumanova UN, Serov VN. Placental lesions in pregnant women with SARS-CoV-2 infection. Akush. Ginekol. 2020;12:44-52. doi: 10.18565/aig.2020.12.44-52. Russian.

4. Bergmann A, Ahmad S, Cudmore M, Gruber AD, Wittschen P, Lindenmaier W, Christofori G, Gross V, Gonzalves A.Ch, Gröne HJ, Ahmed A, Weich HA. Reduction of circulating soluble Flt-1 alleviates preeclampsia-like symptoms in a mouse model. J. Cell. Mol. Med. 2010;14(6B):1857-1867. doi: $10.1111 / \mathrm{j} .1582-4934.2009 .00820 . x$

5. Coronavirus disease 2019 (COVID-19). Situation Report 51. WHO, 11 March 2020. URL: https:/www.who.int/docs/ default-source/coronaviruse/situation-reports/20200311-sitrep51-covid-19.pdf?sfvrsn=1ba62e57_10

6. Di Mascio D, Khalil A, Saccone G, Rizzo G, Buca D, Liberati M, Vecchiet J, Nappi L, Scambia G, Berghella V, D'Antonio F. Outcome of coronavirus spectrum infections (SARS, MERS, COVID-19) during pregnancy: a systematic review and metaanalysis. Am. J. Obstet. Gynecol. MFM. 2020;2(2):100107. doi: 10.1016/j.ajogmf.2020.100107

7. Heazell AE, Moll SJ, Jones CJ, Baker PN, Crocker IP. Formation of syncytial knots is increased by hyperoxia, hypoxia and reactive oxygen species. Placenta. 2007;28(Suppl A):S33-S40. doi: $10.1016 /$ j.placenta.2006.10.007

8. Hoffmann M, Kleine-Weber H, Schroeder S, Krüger N, Herrler T, Erichsen S, Schiergens TS, Herrler G, Wu NH, Nitsche A, Müller MA, Drosten C, Pöhlmann S. SARS-CoV-2 Cell Entry Depends on ACE2 and TMPRSS2 and Is Blocked by a Clinically Proven Protease Inhibitor. Cell. 2020;181(2):271-280.e8. doi: $10.1016 /$ j.cell.2020.02.052 
9. Hunter A, Aitkenhead M, Caldwell C, McCracken G, Wilson D, McClure N. Serum levels of vascular endothelial growth factor in preeclamptic and normotensive pregnancy. Hypertension. 2000;36(6):965-969. doi: 10.1161/01.hyp.36.6.965

10. Juan J, Gil MM, Rong Z, Zhang Y, Yang H, Poon LC. Effect of coronavirus disease 2019 (COVID-19) on maternal, perinatal and neonatal outcome: systematic review. Ultrasound Obstet. Gynecol. 2020;56(1):15-27. doi: 10.1002/uog.22088

11. Khalid ME, Ali ME, Ali KZ. Full-term birth weight and placental morphology at high and low altitude. Int. J. Gynaecol. Obstet. 1997;57(3):259-265. doi: 10.1016/s0020-7292(97)00067-2

12. Mendoza M, Garcia-Ruiz I, Maiz N, Rodo C, Garcia-Manau P, Serrano B, Lopez-Martinez RM, Balcells J, Fernandez-Hidalgo N, Carreras E, Suy A. Pre-eclampsia-like syndrome induced by severe COVID-19: a prospective observational study. BJOG. 2020;127(11):1374-1380. doi: 10.1111/1471-0528.16339
13. Mokhtari T, Hassani F, Ghaffari N, Ebrahimi B, Yarahmadi A, Hassanzadeh G. COVID-19 and multiorgan failure: A narrative review on potential mechanisms. J. Mol. Histol. 2020;51(6):613-628. doi: 10.1007/s10735-020-09915-3

14. Redline RW, Boyd T, Campbell V, Hyde S, Kaplan C, Khong TY, Prashner HR, Waters BL; Society for Pediatric Pathology, Perinatal Section, Maternal Vascular Perfusion Nosology Committee. Maternal vascular underperfusion: nosology and reproducibility of placental reaction patterns. Pediatr. Dev. Pathol. 2004;7(3):237-249. doi: 10.1007/s10024003-8083-2

15. Su M, Hu Z, Dong C, Xu X. Vascular endothelial growth factor gene polymorphisms and hypertensive disorder of pregnancy: A meta-analysis. Pregnancy Hypertens. 2019;17:191-196. doi: 10.1016/j.preghy.2019.05.012 